\title{
PREVALÊNCIA DE MÁ-OCLUSÃO NA DENTADURA DECÍDUA E MISTA NO DISTRITO DE ENTRE RIOS, GUARAPUAVA-PR
}

\author{
PREVALENCE OF MALOCCLUSION IN THE DECIDUOUS AND \\ MIXED DENTITION AT THE DISTRICT OF ENTRE RIOS IN \\ THE CITY OF GUARAPUAVA-PR
}

\author{
Rosana Cecília de Biázio ${ }^{*}$, Gilce Czlusniak Costa ${ }^{2}$, \\ Jorim Sousa das Virgens Filho ${ }^{3}$ \\ 1* Autor para contato: Rua Quatro, 1220 - apto. 30, Colônia Vitória - Entre Rios, 85139-400, \\ Guarapuava, PR; e-mail: biaziorosana@yahoo.com.br \\ 2 Associação Brasileira de Odontologia - ABO/PG-PR Curso de Especialização em \\ Odontopediatria \\ 3 Universidade Estadual de Ponta Grossa - UEPG, Departamento de Odontologia, \\ Campus em Uvaranas, Ponta Grossa, PR
}

Recebido para publicação em 08/10/2004

Aceito para publicação em 01/06/2005

\section{RESUMO}

O objetivo deste estudo foi determinar a prevalência de má-oclusão e a sua distribuição quanto ao gênero e a idade, em crianças de 3 a 9 anos no Distrito de Entre Rios em Guarapuava-PR. No estudo participaram 49 crianças no estágio da dentadura decídua completa, 21 eram do gênero feminino e 28 eram do gênero masculino; das 77 crianças no estágio da dentadura mista, 39 eram do gênero feminino e 38 eram do gênero masculino. Os exames foram realizados por um único profissional em ambiente sob luz natural. Os resultados na dentadura decídua mostraram que apenas $24,5 \%$ da amostra apresentou oclusão normal e que a maioria, 75,5\%, apresentou má-oclusão. No que se refere à distribuição de máoclusão, prevaleceu a de Classe I (67,5\%), seguida pela Classe II (29,8\%) e, finalmente, pela Classe III (2,7\%). Quanto aos resultados na dentadura mista a oclusão normal apresentou-se em 23,4\% da amostra, enquanto o restante, 76,6\%, apresentou má-oclusão. Houve uma maior prevalência de má-oclusão de Classe I (74,5\%), seguida pela Classe II (20,2\%) e Classe III (5,1\%). Em ambos os estágios, a má-oclusão não exibiu diferenças significantes em relação ao gênero. Encontrou-se uma redução de prevalência de má-oclusão em crianças de mais idade.

Palavras-chave: má-oclusão, dentadura decídua, dentadura mista 


\begin{abstract}
The objective of this study was to determine the prevalence of malocclusion and its distribuition (sex and age) in children 3 to 9 years old in the District of Entre Rios in the City of Guarapuava-PR. The sample consisted of the deciduous dentitions of 49 children of both sexes, 21 females and 28 males. In the group of 77 children with a mixed dentition, 39 were females and 38 males.The exams were perfomed by only one professional. The results in the deciduous dentition show that only $24,5 \%$ of sample presented normal occlusion and $75,5 \%$ presented malocclusion. Classification of malocclusion: $67,5 \%$ were CL I, 29,8\% were CL II, $2,7 \%$ were CL III. In the mixed dentition group only $23,4 \%$ of the sample presented normal occlusion. The remaining 76,6\% presented malocclusion. According to the Angle's classification: 74,5\% were CL I, 20,2\% were CL II and $5,1 \%$ were CL III. Both dentition, the results of this study showed no significant statistic differences in regards to the prevalence of malocclusion between the two sexes. Also, there was reduction of malocclusion in older children.
\end{abstract}

Key words: malocclusion, deciduous dentition, mixed dentition

\section{Introdução e objetivo}

No desenvolvimento do ser humano, ocorrem mudanças dimensionais, morfológicas e estruturais em todo o organismo e, particularmente, na face. As condições morfológicas da oclusão nas dentaduras decídua, mista e permanente são inicialmente determinadas pela genética e posteriormente sofrem grande influência dos fatores ambientais. Dessa forma, os vários fatores etiológicos da má-oclusão podem afetar a oclusão já na fase da dentadura decídua e, se não interceptados precocemente, podem resultar em desvios que comprometerão o futuro da oclusão na dentadura permanente.

A OMS (Organização Mundial de Saúde 1955) considera a má-oclusão como o $3^{\circ}$ problema de saúde pública, dada a sua grande incidência e o seu caráter de aparecimento precoce. Galvão, Pereira e Bello (1994) fizeram algumas considerações de natureza antropológica e apresentaram alguns trabalhos epidemiológicos sobre a incidência de má-oclusão na América Latina. Observaram que as pesquisas são escassas, de natureza regional e não obedecem a uma metodologia uniforme, e que os percentuais de máoclusão raramente estavam abaixo de 50\%.
A tentativa de se criar condições para o controle das anormalidades oclusais, por meio de medida preventiva, segundo Barmes (1970), só é possível a partir do conhecimento dos vários aspectos do problema, sua quantificação e necessidade de tratamento nas várias populações.

O objetivo deste trabalho, foi avaliar a oclusão de crianças (3 a 9 anos) no estágio da dentadura decídua completa e mista ( $1^{\circ}$ período transitório e período intertransitório) no Distrito de Entre Rios, GuarapuavaPR. A finalidade foi verificar a prevalência de máoclusão e a sua distribuição segundo o gênero e a idade.

\section{Revisão de literatura}

Por volta de 1913, surgiu um estudo pioneiro sobre más-oclusões na dentadura decídua, desenvolvido por Chiavarro, em Roma, Itália. O autor examinou 1000 crianças, entre 3 e 6 anos, e encontrou um percentual de 28,9\% de má-oclusão sendo distribuída em Classe I (22,2\%), em Classe II (4,1\%) e em Classe III (2,6\%).

Emrich, Brodie e Blayney (1965) avaliaram 
11036 crianças de 6 a 8 anos, de ambos os sexos, da raça branca e negra, em Illinois. No total da amostra, encontraram 69\% de oclusão normal e 31\% de máoclusão. A má-oclusão de Classe I esteve presente em 19\%, seguida pela Classe II (11\%) e Classe III (1\%). Em relação ao grupo racial, não houve diferença na prevalência de má-oclusão, mas no que se refere à sua distribuição, as crianças brancas exibiram um maior percentual de má-oclusão de Classe II em relação às negras. Os autores observaram que não houve diferença entre os gêneros.

Infante (1975) selecionou 735 crianças ( $21 \frac{1}{2}$ a 6 anos) pertencentes aos grupos raciais branco, negro e índio. A relação molar de Classe I foi observada em 79,9\% das crianças brancas, $88,7 \%$ das negras e 89,3\% das índias. A má-oclusão de Classe II esteve presente em $19,1 \%$ das brancas, em 4,3\% das negras e em 2,7\% das índias. Já a má-oclusão de Classe III apresentou-se em $1 \%$ das brancas, 7,1\% das negras e em $8 \%$ das índias. Conclui, portanto, que as crianças brancas exibiram uma maior prevalência de má-oclusão de Classe II comparadas com as negras e índias, e o oposto foi observado em relação a má-oclusão de Classe III.

Um total de 3630 escolares, entre $61 \frac{1}{2}$ a 13 1/2 anos, participaram da pesquisa de Saturno (1980) em Caracas,Venezuela. Os resultados mostraram uma prevalência de oclusão ideal em 1,60\%, oclusão normal em $21,20 \%$ e de má-oclusão em $67,20 \%$, sendo distribuída em 57,5\% de má-oclusão de Classe I, $12,30 \%$ para a de Classe II $1^{\text {a }}$ divisão, 3,60\% para a de Classe II $2^{\text {a }}$ divisão e 3,80\% para a Classe III. De acordo com a faixa etária, aos 7 anos: oclusão ideal em 3,4\%, oclusão normal em 28\%, má-oclusão de: CL I- 58,9\%, CL II $1^{\text {a }}$ divisão- 3,9\%, CL II $2^{\text {a }}$ divisão1,9\% e CL III- 3,9\%; aos 8 anos: oclusão ideal em $1,4 \%$, oclusão normal em 22,2\%, má-oclusão de: CL I- 60,3\%, CL II $1^{\text {a }}$ divisão- 9,6\%, CL II $2^{\text {a }}$ divisão2,1\% e CL III- 4,4\%; aos 9 anos: oclusão ideal em $1,3 \%$, oclusão normal em $15,1 \%$, má-oclusão de: CL I- 66,1\%, CL II $1^{\text {a }}$ divisão- 13,1\%, CL II $2^{\text {a }}$ divisão2,1\% e CL III- 2,1\%; aos 10 anos: oclusão ideal em 0,9\%, oclusão normal em 24,6\%, má-oclusão de: CL I- 53,2\%, CL II $1^{\text {a }}$ divisão- 12,4\%, CL II $2^{\text {a }}$ divisão4,6\% e CL III- 4,3\%; aos 11 anos: oclusão ideal em 0,7\%, oclusão normal em 18,5\%, má-oclusão de: CL
I- 53,9\%, CL II $1^{\text {a }}$ divisão- 18,6\%, CL II $2^{\text {a }}$ divisão4,9\% e CL III- 3,4\%; aos 12 anos: oclusão ideal em $1,8 \%$, oclusão normal em 21,8\%, má-oclusão de: CL I- 52,8\%, CL II $1^{\text {a }}$ divisão- 15,2\%, CL II $2^{\text {a }}$ divisão5\% e CL III- 3,4\%; aos 13 anos: oclusão ideal-1,7\%, oclusão normal- 18,2\%, má-oclusão de: CL I- 54,4\%, CL II $1^{\text {a }}$ divisão- 14,9\%, CL II $2^{\text {a }}$ divisão- 5,4\% e CL III- 5,4\%. Com o aumento da faixa etária, houve uma redução de má-oclusão de Classe I e aumento de Classe II. Em relação ao gênero, não foi encontrada diferença significante.

Maia (1987), após um estudo em 351 crianças (3 a 6 anos em dentadura decídua) em Natal, Rio Grande do Norte, encontrou um percentual de oclusão normal em 42,7\% das crianças e 57,3\% de má-oclusão. O autor observou que a má-oclusão de Classe I esteve presente em 17,95\%, a Classe II em 34,8\% e a Classe III em 4,6\%. De acordo com a faixa etária, encontrou aos 3-4 anos a oclusão normal em 40\% e má-oclusão em $60 \%$, sendo má-oclusão de Classe I em $12,7 \%$, a Classe II em 47,3\%; aos 4-5 anos a oclusão normal em 36,3\% e a má-oclusão em 63,7\% distribuídas em Classe I (18,6\%), Classe II (39,2\%) e Classe III (5,9\%); aos 5-6 anos a oclusão normal em 46,9\% e a má-oclusão em 53,1\% sendo Classe I em 19,1\%, a Classe II em 28,9\% e a Classe III em 5,1\%. O autor concluiu não existir diferença estatística quanto ao gênero em relação ao percentual de má-oclusão e nos tipos de oclusão. A prevalência de má-oclusão diminuiu com a idade. Dentro dos grupos etários, enquanto a má-oclusão de Classe I aumentou o oposto foi observado em relação a Classe II.

Silva Filho, Freitas e Cavassan (1989) avaliaram 2416 escolares em Bauru, São Paulo, de ambos os sexos, na faixa etária entre 7 e 11 anos, provenientes de escolas públicas e particulares. Os resultados mostraram que apenas $11,47 \%$ da população estudada apresentou características de oclusão normal e a maioria, 88,53\%, apresentou algum tipo de desvio. Das más-oclusões a Classe I representou 55\%, seguida da Classe II (42\%) e Classe III (3\%). Mais da metade dos casos de CL II 27\% não apresentaram comprometimento facial, denotando um bom relacionamento entre as bases apicais. Das más-oclusões CL II esqueléticas, $15 \%, 11,5 \%$ eram CL II $1^{\text {a }}$ divisão e apenas 3,5\% CL II $2^{a}$ divisão. A condição sócio-econômica 
influenciou o percentual de oclusão normal e de máoclusão de Classe I. As classes mais inferiores exibiram um aumento de má-oclusão de Classe I em detrimento da oclusão normal.

Braga e Alves (1998) estudaram a prevalência de má-oclusão em 264 crianças (5 a 7 anos em dentadura decídua e mista) e 212 crianças (12 e 13 anos), em Belo Horizonte, Minas Gerais. Houve uma redução de oclusão normal de $14 \%$ na faixa etária mais jovem para 6\% nas crianças de 12-13 anos. A má-oclusão de CL I foi a de maior prevalência, estando presente em $41 \%$, seguida da CL II $1^{\text {a }}$ divisão em 37\%, CL III em 7\% e CL II $2^{\text {a }}$ divisão em 5\%. A má-oclusão de CL I aumentou de 36\% para 48\% na faixa etária mais alta e tal fato deve-se ao aumento das perdas dentárias, problemas de espaço, apinhamento, giroversões, desvios de linha média e outros agravantes. Tanto a CL II $1^{\text {a }}$ divisão (36\%) quanto a CL II $2^{\mathrm{a}}$ divisão (4\%) mantiveram seus índices inalterados nos dois grupos estudados. A má-oclusão de CL III sofreu um ligeiro decréscimo de $10 \%$ para $6 \%$ na faixa etária mais alta, resultado esperado, já que a CL III, na maioria dos casos, é um problema ósseo, com padrão familiar, apenas acentuando suas características com a idade. E em relação à distribuição de má-oclusão, a Classe I aumentou com a idade, a Classe II apresentou uma relativa estabilidade e a Classe III apresentou um ligeiro decréscimo.

Em Lueven, Bélgica, Carvalho e Vinker (1998) avaliaram 750 crianças, 3 a 5 anos. Do total da amostra, 55,73\% apresentaram oclusão normal e 44,26\% apresentaram má-oclusão.

Ramos et al (2000) examinaram 218 crianças de 6 a 12 anos em Porto Rico, Paraná. A oclusão normal apresentou-se em $11 \%$ das crianças e a má-oclusão em 89\%. A má-oclusão de Classe I esteve presente em $52 \%$, a Classe II $1^{\text {a }}$ divisão em $41 \%$, a Classe II $2^{\text {a }}$ divisão em 3\%, a Classe III em 4\%.

Branco (2002) realizou um estudo de prevalência de más-oclusões de Angle em 1767 escolares da rede estadual de ensino em Ponta Grossa, Paraná, entre 8 e 12 anos. Segundo a Classificação de Angle, a amostra apresentou 33,8\% de CL I, 55,35\% de CL II $1^{\text {a }}$ divisão, 6,1\% de CL II $2^{\text {a }}$ divisão e 4,75\% de CL III. Não foram encontradas diferenças significantes quanto ao gênero.
Lenci Jesus (2002) examinou 219 crianças entre 3 a 6 anos e encontrou um percentual de oclusão normal em 30,6\% e de má-oclusão em 69,4\% da amostra.

Em um estudo realizado em Bauru, São Paulo, Silva Filho et al (2002) avaliaram a oclusão em 2016 crianças entre 3 a 6 anos. Apenas 26,4\% das crianças apresentaram oclusão normal. O restante, $73,26 \%$ da população estudada, exibiu algum padrão de máoclusão. A amostra não apresentou diferença entre os sexos em relação à presença ou ausência de má-oclusão. A má-oclusão distribuiu-se em 33,65\% de Classe I, 26,74\% de Classe II e 2,93\% de Classe III.

\section{Material e método}

\subsection{Material}

A amostra do presente estudo abrangeu 126 crianças de 3 a 9 anos, das quais 49 se encontravam no estágio da dentadura decídua completa e 77 no estágio da dentadura mista. O critério clínico para a seleção da amostra foi incluir crianças que estivessem na fase da dentadura decídua completa e dentadura mista $\left(1^{\circ}\right.$ período transitório e no período intertransitório). $\mathrm{O}$ critério para a exclusão da amostra incluiu as crianças que usavam aparelho ortodôntico ou que já tinham sido submetidas a essa terapia, as não autorizadas pelos pais, além das crianças fora do período de oclusão estabelecido. Previamente ao exame clínico, realizouse uma palestra educativa sobre higiene bucal buscando uma aproximação com o examinador. Em seguida foram distribuídas duas fichas aos 374 responsáveis: uma ficha de consentimento livre e esclarecido (para que permitisse a participação da criança no levantamento) e outra de coleta de dados (para obtenção de dados sobre a história médica e odontológica).

\subsection{Método}

Os exames foram realizados por um único profissional, em um ambiente onde havia incidência direta de luz natural. A criança permanecia sentada de frente para o examinador com o Plano de Frankfurt paralelo ao solo e em máxima intercuspidação habitual. Previa- 
mente ao exame intra-bucal realizou-se a análise facial (padrão facial, tipo facial), com o propósito de observar desequilíbrios musculares que pudessem afetar o contorno da face.

O exame intra-bucal foi realizado com o auxílio de espátula de madeira (para afastar lábios e bochechas) e luva cirúrgica, ambas descartáveis.

A anotação dos dados na ficha de registro, especialmente desenvolvida para este estudo, seguiu determinadas normas:

1. Classificação da oclusão: na dentadura decídua baseou-se na relação do plano terminal dos $2^{\text {os }}$ molares decíduos, segundo Baume, e na relação de caninos decíduos de acordo com a classificação de Foster e Hamilton, adaptadas à classificação de Angle. Na dentadura mista utilizou-se a classificação de Angle, a qual levava em consideração a relação dos $1^{\text {os }}$ molares permanentes.

2. A oclusão era considerada normal quando se encontrava em Classe I e sem qualquer desvio.

3. Foram feitas anotações dos desvios oclusais encontrados.

Os dados da amostra obtidos através dos exames clínicos foram considerados classificatórios, obedecendo a critérios já estabelecidos, na dentadura decídua (classificação de Foster e Hamilton e de Baume) e na dentadura mista (classificação de Angle). Os procedimentos estatísticos utilizados para a análise dos dados foram através de análise descritiva, cálculos percentuais e gráficos ilustrativos dos resultados. Essa análise foi não-paramétrica, utilizando o teste do quiquadrado para verificar a hipótese da não existência de correlação entre sexo e idade na oclusão. Através do coeficiente de contingência verificou-se a intensidade dessa relação.

\section{Resultados}

Os resultados obtidos em ambos os estágios da oclusão pesquisada estão mostrados abaixo:

Tabela 1 - Distribuição de prevalência de má-oclusão na dentadura decídua

\begin{tabular}{|c|c|c|c|c|c|c|}
\hline \multicolumn{7}{|c|}{ Sexo } \\
\hline \multicolumn{2}{|c|}{ Má-oclusão } & Feminino & \multicolumn{2}{|c|}{ Masculino } & \multicolumn{2}{|c|}{ Total } \\
\hline & $N$ & $P$ & $N$ & $P$ & $N$ & $\boldsymbol{P}$ \\
\hline Sim & 16 & $76 \%$ & 21 & $75 \%$ & 37 & $75,5 \%$ \\
\hline Não & 05 & $24 \%$ & 07 & $25 \%$ & 12 & $24,5 \%$ \\
\hline Total & 21 & & 28 & & 49 & \\
\hline
\end{tabular}

$p=0,9236$ ( Teste de $\mathrm{x}^{2}$ )

$C=0,0137$ ( Coeficiente de Contingência )

Tabela 2 - Distribuição de freqüência de má-oclusão de angle, por gênero, na dentadura decídua

\begin{tabular}{|c|c|c|c|c|}
\hline \multirow{3}{*}{$\begin{array}{l}\text { Má-oclusão } \\
\text { de Angle }\end{array}$} & \multicolumn{4}{|c|}{ Distribuição de freqüência } \\
\hline & \multicolumn{2}{|c|}{ Feminino } & \multicolumn{2}{|c|}{ Masculino } \\
\hline & $\mathrm{n}$ & $\mathrm{p}$ & $\mathrm{n}$ & $\mathrm{p}$ \\
\hline$\overline{\mathrm{CL} \mathrm{I}}$ & 11 & $68,8 \%$ & 14 & $66,7 \%$ \\
\hline $\mathrm{CL}$ II $1^{\mathrm{a}}$ divisão & 3 & $18,8 \%$ & 3 & $14,3 \%$ \\
\hline CL II $1^{\mathrm{a}}$ divisão Subdivisão & 2 & $12,5 \%$ & 2 & $9,5 \%$ \\
\hline CL II $2^{\mathrm{a}}$ divisão Subdivisão & - & - & 1 & $4,8 \%$ \\
\hline CL III & - & - & 1 & $4,8 \%$ \\
\hline Total & 16 & $100 \%$ & 21 & $100 \%$ \\
\hline
\end{tabular}




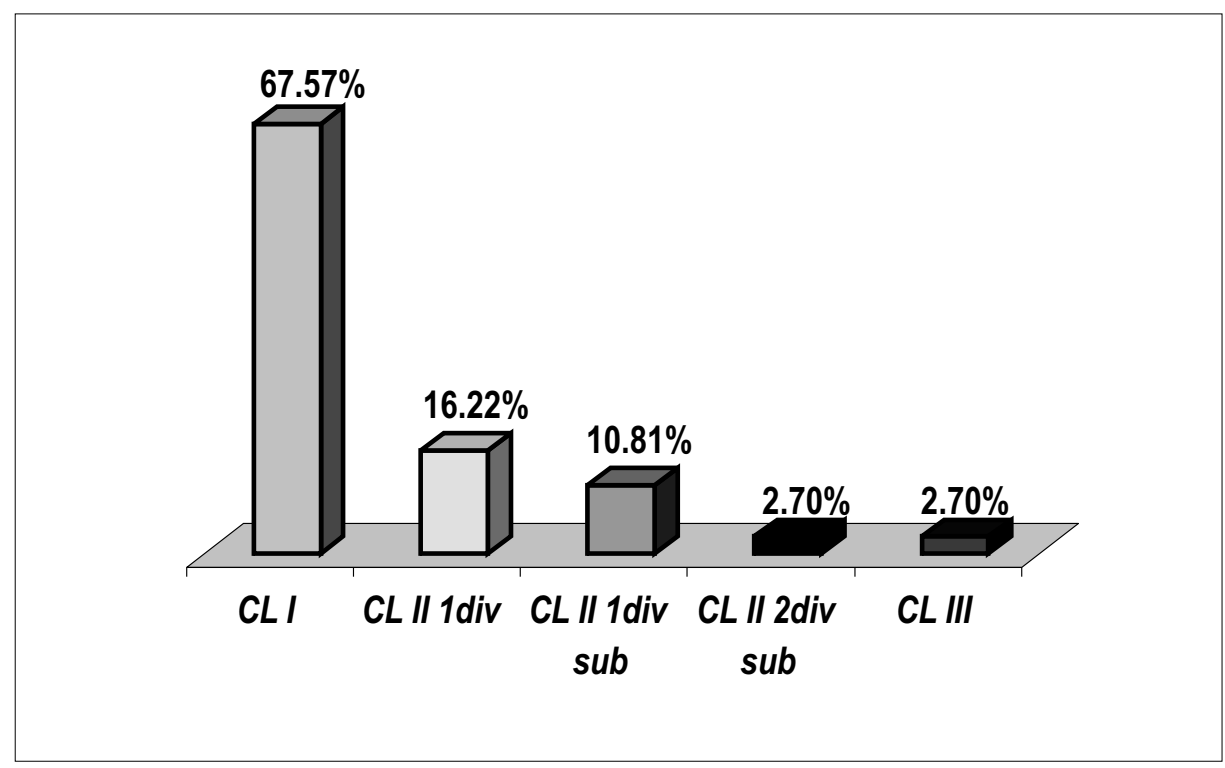

Fonte: Pesquisa de campo Notas: CL II 1div- CL II $1^{\text {a divisão }}$

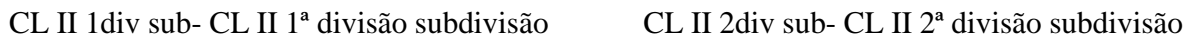

Gráfico 1 - Distribuição de frequêencia de má-oclusão de angle na dentadura decídua

Tabela 3 - Distribuição de prevalência de oclusão normal e má-oclusão segundo a idade na população pesquisada

\begin{tabular}{llcccc}
\hline \multicolumn{1}{c}{ Idade } & \multicolumn{3}{c}{ Oclusão } \\
\hline & \multicolumn{2}{c}{ Normal } & Má-oclusão & Total \\
\hline anos & $\boldsymbol{N}$ & $\boldsymbol{P}$ & $\boldsymbol{N}$ & 10 \\
$\mathbf{4}$ anos & 03 & $30 \%$ & 07 & $70 \%$ & 12 \\
$\mathbf{5}$ anos & 01 & $8,3 \%$ & 11 & $91,7 \%$ & 19 \\
$\mathbf{6}$ anos & 04 & $21 \%$ & 15 & $79 \%$ & 08 \\
\hline Total & 04 & $50 \%$ & 37 & $50 \%$ & 49 \\
\hline
\end{tabular}

$p=0,1875\left(\right.$ Teste de $\left.\mathrm{x}^{2}\right)$

$C=0,2986$ ( Coeficiente de Contingência )

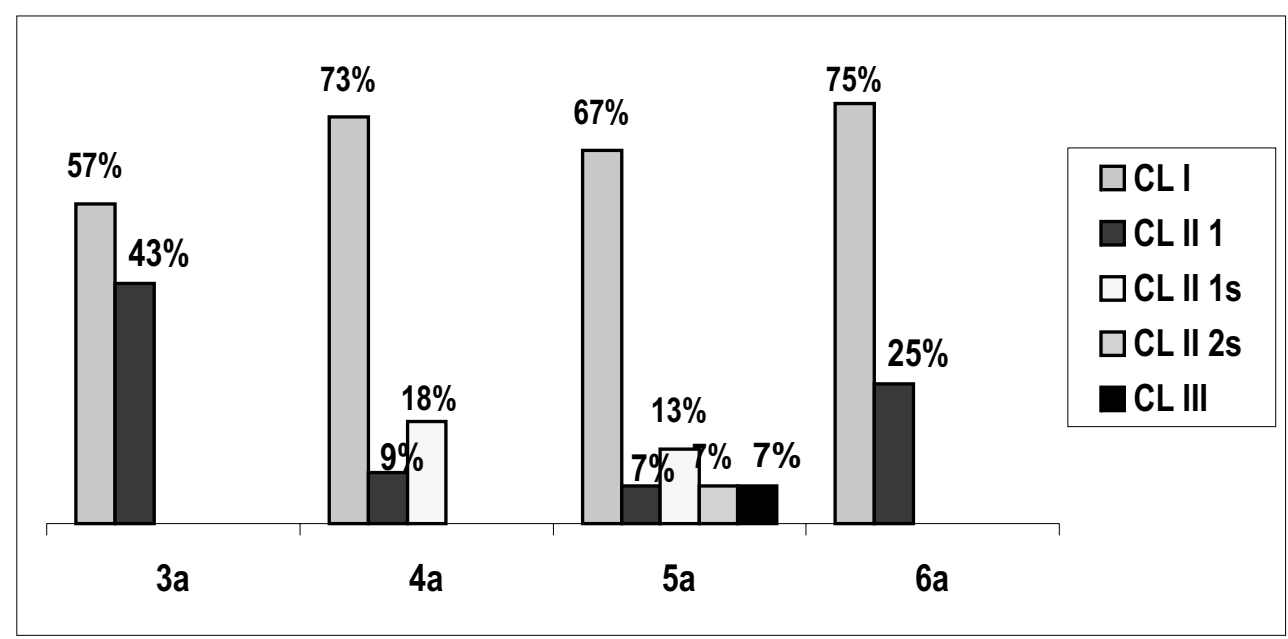

Gráfico 2 - Distribuição de freqüência de má-oclusão de angle, por idade, na população pesquisada

Publ. UEPG Biol. Health Sci., Ponta Grossa, 11 (1): 29-38, mar. 2005 
Tabela 4 - Distribuição de prevalência de má-oclusão na dentadura mista

\begin{tabular}{|c|c|c|c|c|c|c|}
\hline \multirow{3}{*}{ Má-oclusão } & \multicolumn{6}{|l|}{ Sexo } \\
\hline & \multicolumn{2}{|c|}{ Feminino } & \multirow{2}{*}{$\begin{array}{c}\text { Masculino } \\
\mathrm{N}\end{array}$} & \multicolumn{3}{|c|}{ Total } \\
\hline & $\mathrm{N}$ & $\mathrm{P}$ & & $\mathrm{P}$ & $\mathrm{N}$ & $\mathrm{P}$ \\
\hline Sim & 28 & $72 \%$ & 31 & $81,5 \%$ & 59 & $76,6 \%$ \\
\hline Não & 11 & $28 \%$ & 07 & $18,5 \%$ & 18 & $23,4 \%$ \\
\hline Total & 39 & $50,6 \%$ & 38 & $49,4 \%$ & 77 & $100 \%$ \\
\hline
\end{tabular}

Tabela 5 - Distribuição de freqüência de má-oclusão de angle, por gênero, na dentadura mista

\begin{tabular}{|c|c|c|c|c|}
\hline \multirow{3}{*}{$\begin{array}{l}\text { Má-oclusão } \\
\text { de Angle }\end{array}$} & \multicolumn{4}{|c|}{ Distribuição de freqüência } \\
\hline & \multicolumn{2}{|c|}{ Feminino } & \multicolumn{2}{|c|}{ Masculino } \\
\hline & $\mathrm{n}$ & $\mathrm{p}$ & $\mathrm{n}$ & $\mathrm{p}$ \\
\hline CL I & 22 & $78,57 \%$ & 22 & $70,97 \%$ \\
\hline CL II $1^{\mathrm{a}}$ divisão & 2 & $7,14 \%$ & 4 & $12,9 \%$ \\
\hline CL II $1^{a}$ divisão Subdivisão & 3 & $10,71 \%$ & 2 & $6,45 \%$ \\
\hline CL II $2^{\mathrm{a}}$ divisão Subdivisão & - & - & 1 & $3,23 \%$ \\
\hline CL III Subdivisão & - & - & 2 & $6,45 \%$ \\
\hline CL III & 1 & $3,57 \%$ & - & - \\
\hline Total & 28 & $100 \%$ & 31 & $100 \%$ \\
\hline
\end{tabular}

Fonte: Pesquisa de campo

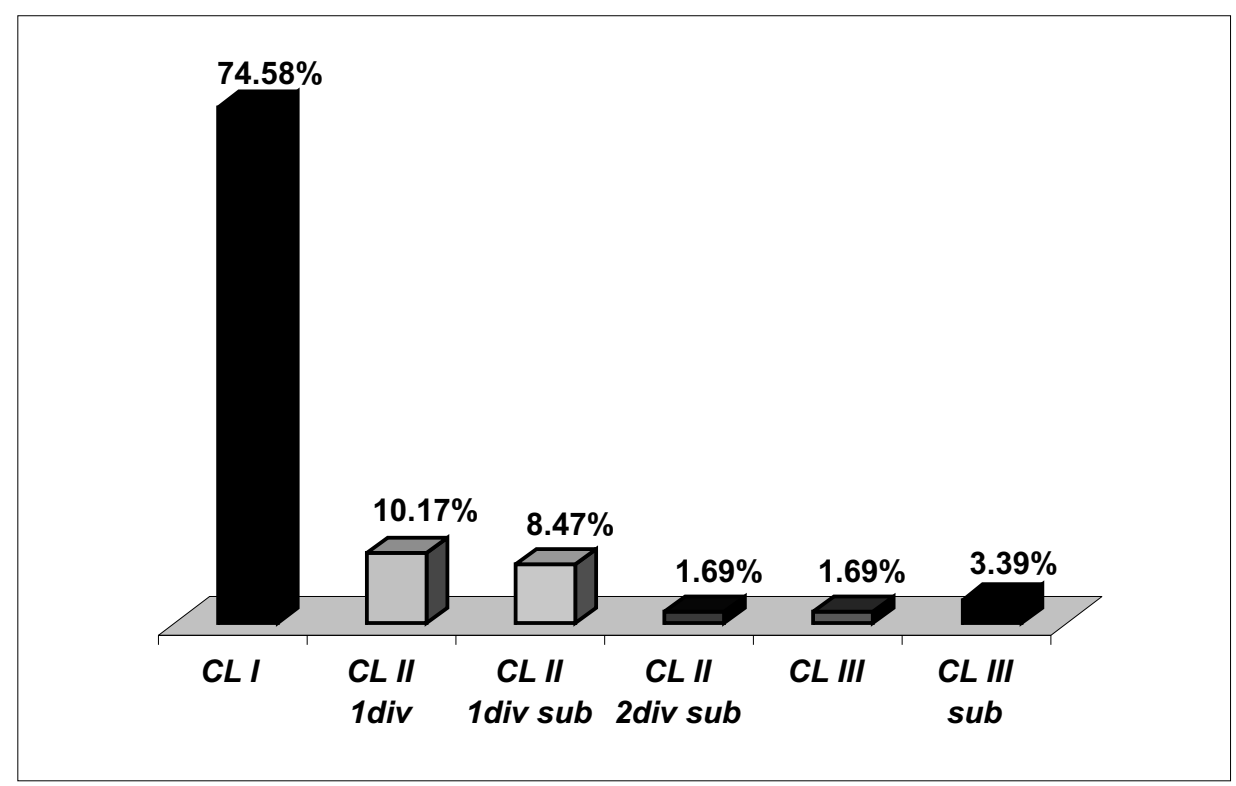

Gráfico 3 - Distribuição de freqüência de má-oclusão de angle na dentadura mista 
Tabela 6 - Distribuição de prevalência de oclusão normal e má-oclusão segundo a idade, na dentadura mista

\begin{tabular}{|c|c|c|c|c|c|}
\hline \multirow{3}{*}{ Idade } & \multicolumn{4}{|c|}{ Oclusão } & \multirow{3}{*}{ Total } \\
\hline & \multicolumn{2}{|c|}{ Normal } & \multicolumn{2}{|c|}{ Má-oclusão } & \\
\hline & $\mathrm{N}$ & $\mathrm{P}$ & $\mathrm{N}$ & $\mathrm{P}$ & \\
\hline 5 anos & 02 & $18 \%$ & 09 & $82 \%$ & 11 \\
\hline 6 anos & 09 & $31 \%$ & 20 & $69 \%$ & 29 \\
\hline 7 anos & 03 & $25 \%$ & 09 & $75 \%$ & 12 \\
\hline 8 anos & 01 & $9 \%$ & 10 & $91 \%$ & 11 \\
\hline 9 anos & 03 & $21,5 \%$ & 11 & $78,5 \%$ & 14 \\
\hline Total & 18 & & 59 & & 77 \\
\hline
\end{tabular}

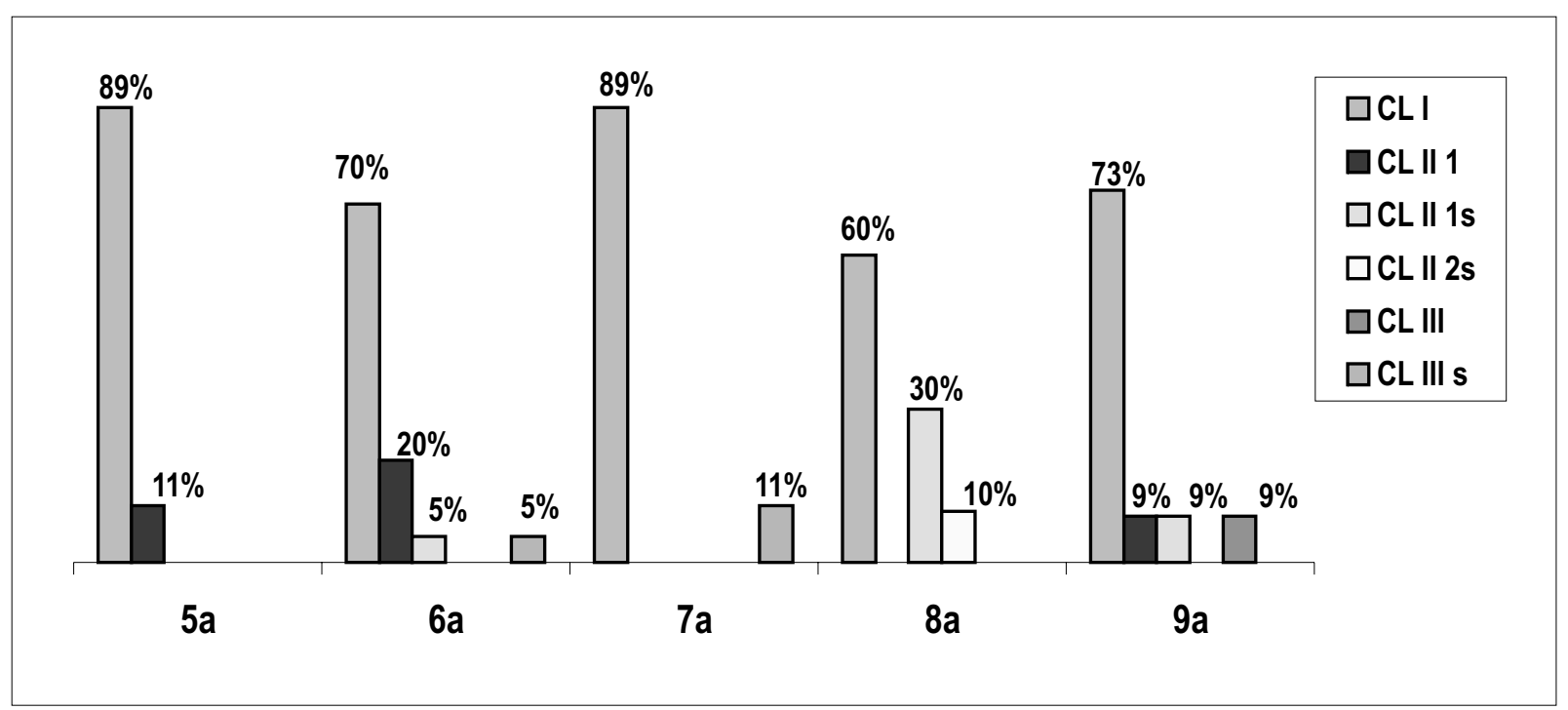

Gráfico 4 - Distribuição de má-oclusão de angle de acordo com a idade

\section{Discussão}

As tabelas 01 e 04 mostram que houve predomínio de má-oclusão em ambos os estágios da oclusão estudados. Esses resultados foram similares aos estudos de Maia (1987), Silva Filho, Freitas e Cavassan (1989), Braga e Alves (1998), Ramos et al (2000), Lenci Jesus (2002) e Silva Filho et al (2002); e divergiram dos trabalhos de Chiavarro (1913), Emrich, Brodie e Blayney (1965), Carvalho e Vinker (1998).

Observou-se que, conforme gráficos 01 e 03, a má-oclusão de Classe I foi a mais prevalente, seguida de má-oclusão de Classe II, em especial a de Classe

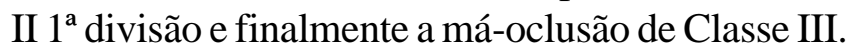

Esses resultados se mostraram compatíveis com as pesquisas de Chiavarro (1913), Emrich, Brodie e Blayney (1965), Infante (1975), Saturno (1980), Silva Filho, Freitas e Cavassan (1989), Ramos et al (2000), Branco (2002), Silva Filho et al (2002); sendo o oposto encontrado no trabalho de Maia (1987).

Houve uma preocupação de vários autores em registrar uma possível diferença na prevalência de másoclusões em relação ao gênero, mas de acordo com a literatura consultada, não foram observadas diferenças significantes, fato esse similar ao deste estudo, no qual, de acordo com os resultados das tabelas 01, 02, 04 e 05, não se encontraram diferenças significativas quanto à prevalência de má-oclusão e nem quanto à distri- 
buição de má-oclusão de Angle.

Ao se analisar a prevalência de má-oclusão em relação à idade, conforme tabelas 03 e 06, observouse que, pela análise do teste do $\mathrm{x}^{2} \mathrm{e}$ o coeficiente de contingência, a má-oclusão ocorre em todas as idades, confirmando o que foi preconizado por Chiavarro (1913).

Em relação à distribuição de freqüência de máoclusão na dentadura decídua (gráfico 02), observouse que, com a idade, houve um aumento de má-oclusão de Classe I e um declínio de má-oclusão de Classe II, sendo compatível com o trabalho de Maia (1987). No que se refere à dentadura mista (gráfico 04), houve redução de má-oclusão de Classe I e um aumento das más-oclusões de Classe II e III, o que foi similar ao trabalho de Saturno (1980) e o oposto foi encontrado no estudo de Braga e Alves (1998).

\section{Conclusões}

Observou-se neste estudo que houve uma alta prevalência de má-oclusão em estágios iniciais da oclusão, revelando a necessidade de se introduzir programas eficazes de prevenção e interceptação, garantindo um desenvolvimento normal ao futuro da oclusão permanente.

Em ambos os estágios da dentadura decídua e mista, não foram encontradas diferenças significantes entre os gêneros. E no que se refere à idade, observouse uma redução no percentual de má-oclusão conforme esta aumentava.

\section{REFERÊNCIAS}

1. ANGLE, E. H. Classification of malocclusion. Dent. Cosmos, Philadelphia, v.41, n.3, p.248-264, 1899.

2. BARMES, D.E. Who basic oral epidemiology methods. Int. J. Orthod. Oral Surg., v. 20, p.570-4, 1970.

3. BAUME, L. J. Physicological tooth migration and its significance for the development of occlusion. II: The biogenesis of accessional dentition. J. Dent. Res. Washington, v.29, n.3, p. 331-337, jun. 1950.
4. BRAGA, M. F.; ALVES, J.B. Prevalência de más oclusões em escolares de nível socioeconômico baixo no município de Belo Horizonte, Minas Gerais. Bios, Cadernos do Departamento de Ciências Biológicas da PUC Minas, v.6, n.6, p.73-82, dez. 1998.

5. BRANCO, A. L. L. Estudo Epidemiológico da prevalência das más-oclusões em estudantes da cidade de Ponta GrossaPr. Curitiba, 2002. 120p. Monografia do curso de Pósgraduação em Ortodontia e Ortopedia Facial do Setor de Ciências da Saúde da Universidade Federal do Paraná.

6. CARVALHO, J. C.; VINKER, F. Malocclusion dental injuries and dental anomalies in the primary dentition of Belgian children. International Journal of Pediatric Dentistry. v.8, n.2, p.137-141, 1998.

7. CHIAVARRO, A. Malocclusions of temporary teeth. Int. J. Orthod., v.1, p.171-179, 1916.

8. EMRICH, R. E.; BRODIE, A. G.; BLAYNEY, J. R. Prevalence of class I, class II and class III malocclusions (Angle) in an urban population: an epidemiological study. J. Dent. Res., Washington, v.44, n.5, p.947-953, sept./oct. 1965.

9. FOSTER, T. D.; HAMILTON, M. C. Occlusion in the primary dentition: study of children at $2 \frac{1}{2} 2$ to 3 years of age. Br. Dent. J., London, v. 26, n.2, p.76-79, jan. 1969.

10. GALVÃO, C. A. N.; PEREIRA, C. B.; BELLO, D. R. M. Prevalência de maloclusões na América Latina e considerações antropológicas. Ortodontia, São Paulo, v.27, n.1, p.51-59, jan./ abr. 1994.

11. INFANTE, P. F. Malocclusion in the deciduous dentition in white, black, and apache Indian children. Angle Orthod., Appleton, v.45, n.3, p.213-218, jul. 1975.

12. LENCI JESUS, P. R. de. Trabalho sobre a incidência de má oclusão entre crianças de 3 a 6 anos. Rev. Dental Press Ortodon. Ortop. Facial, Maringá, v.7, n.1, p.81-83, jan./fev. 2002.

13. MAIA, N.G. Prevalência de más oclusões em pré-escolares da cidade de Natal, na fase da dentição decídua. Natal, 1987. 86p. Dissertação de mestrado em Odontologia Social da Universidade Federal do Rio Grande do Norte.

14. ORGANIZATION MUNDIAL DE LA SALUD. Higiene dental: resenã de una reunion de ym grupo de consultores. Crónica de la OMS, v.9, p.11-16, 1955.

15. RAMOS,A. L.; GASPARETTO, A.; TERADA, H. H.; FURQUIM, L. Z.; BASSO, P.; MEIRELES, R. P. Assistência ortodôntica preventiva-interceptora em escolares do município de Porto Rico. Parte I: Prevalências das más oclusões. Rev. Dental Press Ortod. Ortop. Facial, v.5, n.3, p.9-13, mai./jun. 2000. 
16. SATURNO, L. D’E. de. Características de la oclusion de 3.630 escolares Del área metropolitana de Caracas. Acta Odontológica Venezolana, Caracas, v.18, n.2, p.237-263, may/ ago. 1980.

17. SILVA FILHO, O. G.; FREITAS, S. F.; CAVASSAN, A. de O. Prevalência de oclusão normal e má oclusão na dentadura mista em escolares da cidade de Bauru (São Paulo). Revista da Associação Paulista de Cirurgiões Dentistas. v.43, n.6, p.287290, nov./dez. 1989.

18. SILVAFILHO, O. G. da; SILVA, P. R. B. da; REGO, M. V.N. N. do; SILVA, F. P. L. da; CAVASSAN, A. O. Epidemiologia da má oclusão na dentadura decídua. Ortodontia, São Paulo, v.25, n.1, p.22-33, jan./mar. 2002. 